\title{
Low-Temperature Magnetic Properties of Nanometric Fe-Based Particles
}

\author{
B. David, O. SchneEweiss
}

Intitute of Physics of Materials, AS CR

Žižkova 22, 61662 Brno, Czech Republic

$$
\text { E. ŠAnTAVÁ }
$$

Institute of Physics, AS CR

Na Slovance 2, 18221 Praha 8, Czech Republic

\section{R. Alexandrescu And I. Morjan}

National Institute for Laser, Plasma and Radiation Physics

P.O. Box MG-36, 76900 Bucharest, Romania

Fe-based nanoparticles were prepared by laser-driven pyrolysis. The assynthesised powder consists of $\alpha$-Fe and $\mathrm{Fe}_{3} \mathrm{O}_{4} / \gamma-\mathrm{Fe}_{2} \mathrm{O}_{3}$ nanoparticles embedded in a pyrolytic carbon matrix. The crystallite size of $1.8 \mathrm{~nm}$ for $\alpha$-Fe was calculated using the Scherrer formula. The as-synthesised nanopowder was superparamagnetic. The maximum of the zero-field cooling curve was observed at $32 \mathrm{~K}$ and the distribution of blocking temperatures $g\left(T_{\mathrm{B}}\right)$ peaked at $11 \mathrm{~K}$. As a result of small particle sizes and the soft matrix, the Lamb-Mössbauer factor $f$ was significantly higher at $4 \mathrm{~K}$ than at $293 \mathrm{~K}$.

PACS numbers: 81.16.Mk, 82.30.Lp, 75.50.Bb, 75.75.+a, 61.05.Qr

\section{Introduction}

The method of laser-induced pyrolysis of gases [1] has been recently used for the synthesis of various Fe-based nanopowders, either metallic (for instance $\alpha$-Fe, $\mathrm{Fe}_{3} \mathrm{C}, \mathrm{Fe}_{7} \mathrm{C}_{3}$ ) or oxidic (for example $\alpha-\mathrm{Fe}_{2} \mathrm{O}_{3}, \gamma-\mathrm{Fe}_{2} \mathrm{O}_{3}, \mathrm{Fe}_{3} \mathrm{O}_{4}$ ).

In the present article we describe the structural and low-temperature magnetic properties of a nanopowder with nanometer-sized $\alpha$-Fe, $\mathrm{Fe}_{3} \mathrm{O}_{4}$ and/or $\gamma-\mathrm{Fe}_{2} \mathrm{O}_{3}$ particles. 


\section{Experimental}

The Fe-C-based nanopowder labelled CF26, which was obtained during the series of experiments reported earlier [2], was synthesised by the laser co-pyrolysis of the gas mixture $\mathrm{Fe}(\mathrm{CO})_{5} / \mathrm{C}_{2} \mathrm{H}_{4} / \mathrm{C}_{2} \mathrm{H}_{2}$.

The powder X-ray pattern was obtained with the X'Pert Panalytical diffractometer (Co $\mathrm{K}_{\alpha}$ radiation). The mean coherent domain length $d_{\mathrm{XRD}}$ (crystallite size) was calculated using the Scherrer formula.

Mössbauer spectra were measured in standard transmission geometry with ${ }^{57} \mathrm{Co}$ in $\mathrm{Rh}$ matrix. Isomer shift was evaluated with respect to $\alpha$-Fe.

The physical properties measuring system PPMS 9 from Quantum Design equipped with the P500 AC/DC magnetometry system was used for lowtemperature magnetic measurements.

\section{Results and discussion}

The X-ray diffraction (XRD) pattern of the CF26 sample exhibited very broad diffraction lines. The peak at $2 \theta=29.5^{\circ}$ belonged to (200) planes of graphite $\left(d_{\mathrm{XRD}}=1.6 \mathrm{~nm}\right)$ and the peak at $2 \theta=51.8^{\circ}$ was assigned to (110) planes of $\alpha$-Fe $\left(d_{\mathrm{XRD}}=1.8 \mathrm{~nm}\right)$. The peak of lower intensity at $2 \theta=40.5^{\circ}$ belonged to $\mathrm{Fe}_{3} \mathrm{O}_{4} / \gamma-\mathrm{Fe}_{2} \mathrm{O}_{3}$. The presence of $\mathrm{Fe}-\mathrm{C}$ martensite was not excluded.
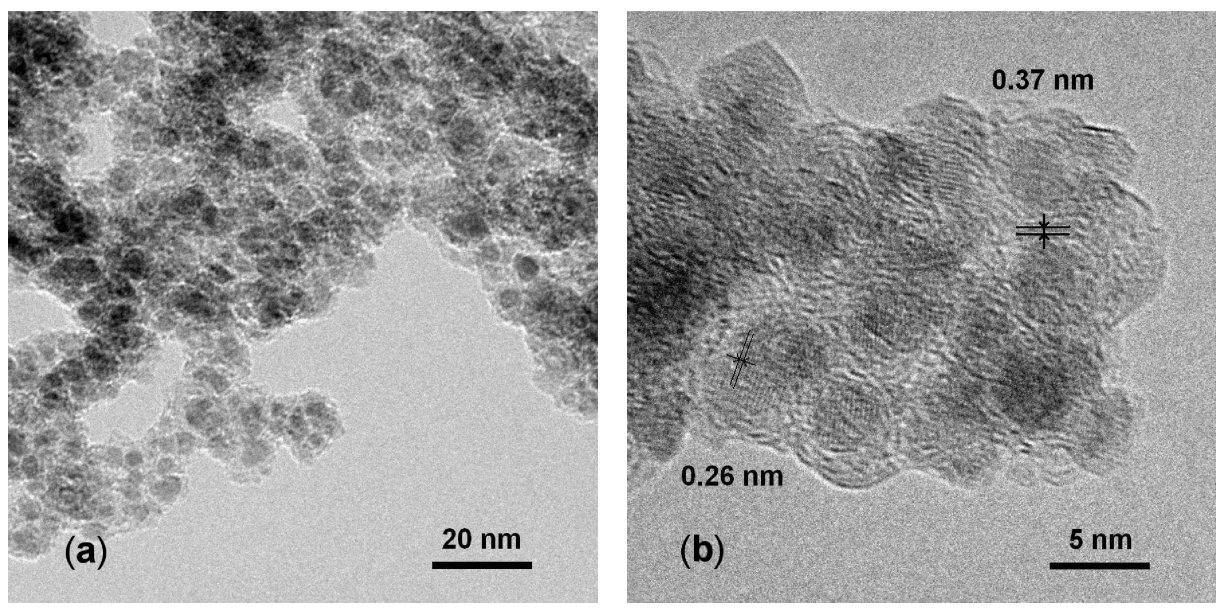

Fig. 1. HRTEM images (a) and (b) for the synthesised CF26 sample.

The high resolution transmission electron microscopy (HRTEM) examination revealed fine morphology of the nanopowder (Fig. 1a) with very small nanoparticles embedded in a matrix. Nanometric particles were identified in the higher resolution image (Fig. 1b) where mainly iron oxide crystalline particles can be seen: the interplanar distance of $0.26 \mathrm{~nm}$ belongs to (311) planes of $\mathrm{Fe}_{3} \mathrm{O}_{4}$ / 
$\gamma-\mathrm{Fe}_{2} \mathrm{O}_{3}$. The interplanar distance of $0.37 \mathrm{~nm}$ identified between particles is assigned to pyrolytic carbon which was generated by the decomposition of $\mathrm{C}_{2} \mathrm{H}_{2}$ [2] .

The hysteresis loop of the sample measured at $293 \mathrm{~K}$ exhibited zero coercivity $H_{\mathrm{C}}$, which was - due to phase composition and particle sizes - the sign of superparamagnetic behaviour [3]. After zero-field cooling (ZFC) we extracted the following values from the hysteresis loop measured at $4 \mathrm{~K}: H_{\mathrm{C}}=65 \mathrm{kA} / \mathrm{m}$, remanence $\sigma_{\mathrm{R}}=7.6 \mathrm{Am}^{2} / \mathrm{kg}$, and saturation $\sigma_{\mathrm{S}}=29.8 \mathrm{Am}^{2} / \mathrm{kg}($ at $7.2 \mathrm{MA} / \mathrm{m})$.

The hysteresis loop measured at $4 \mathrm{~K}$ after cooling of the sample in the field of $7.2 \mathrm{MA} / \mathrm{m}$ was not displaced along the field axis with respect to the hysteresis loop measured at $4 \mathrm{~K}$ after ZEC. Hence core/shell exchange anisotropy effect [4] and spin glass behaviour [5] can be excluded.

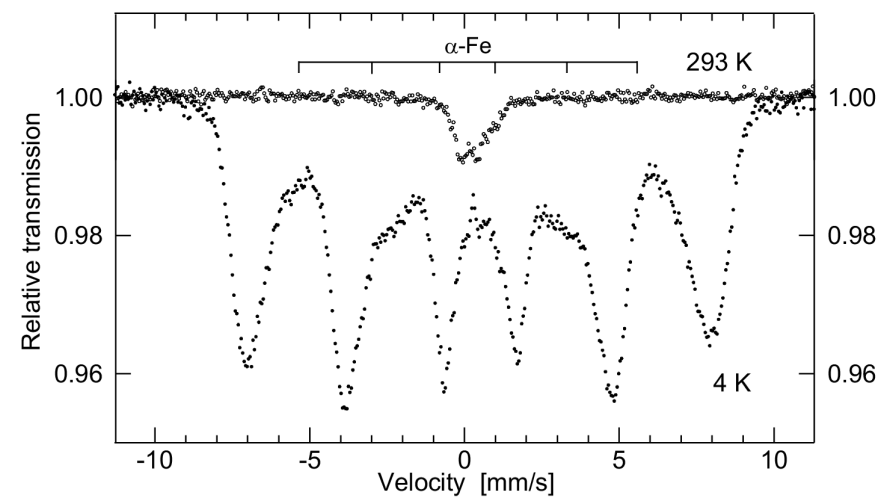

Fig. 2. Mössbauer spectra for the synthesised CF26 sample measured at specified temperatures. The position of the $\alpha$-Fe sextet at $4 \mathrm{~K}$ is indicated.

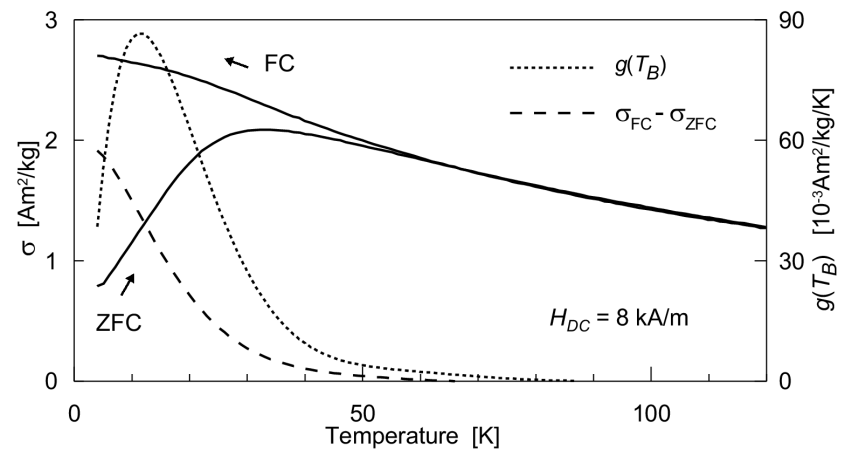

Fig. 3. ZFC and FC curves for the synthesised CF26 sample.

The superparamagnetic character of the nanopowder expresses itself in the measured Mössbauer spectra through the transition to sextets below the blocking 
temperature $T_{\mathrm{B}}[3]$. Therefore the spectrum for our sample measured at $4 \mathrm{~K}$ (Fig. 2) is dominated by the sextets of $\mathrm{Fe}_{3} \mathrm{O}_{4} / \gamma-\mathrm{Fe}_{2} \mathrm{O}_{3}[6]$.

The significant feature of the Mössbauer spectra in Fig. 2 is the increase in the intensity of absorption after cooling down to $4 \mathrm{~K}$. The intensity of the absorption of a given phase depends on its recoil-free fraction $f$ (named the LambMössbauer factor) [7]. The factor $f$ is a function of the Debye temperature, $\Theta_{\mathrm{D}}$, which decreases with decreasing particle size [8]. In our case, due to particle sizes and the soft pyrolytic carbon matrix [9], $\Theta_{\mathrm{D}}$ is significantly lower than $293 \mathrm{~K}$ and therefore $f$ grows by cooling.

Because of particle size distribution, one has to consider the distribution of blocking temperatures $g\left(T_{\mathrm{B}}\right)$, which can be calculated from the measured $\mathrm{ZFC}$ and field cooled (FC) curves (Fig. 3). It holds that $g\left(T_{\mathrm{B}}\right)=\mathrm{d}\left(\sigma_{\mathrm{ZFC}}-\sigma_{\mathrm{FC}}\right) / \mathrm{d} T$ [10]. In our case, the maximum of the $g\left(T_{\mathrm{B}}\right)$ curve is reached at $11 \mathrm{~K}$. The highest value of $\sigma_{\mathrm{ZFC}}$ is observed at $32 \mathrm{~K}$.

\section{Acknowledgments}

This work was supported by the AS CR (AV0Z20410507) and the Ministry of Education, Youth and Sport of the Czech Republic (1M6198959201).

\section{References}

[1] R. Alexandrescu, I. Morjan, F. Dumitrache, I. Voicu, I. Soare, I. Sandu, C.T. Fleaca, Solid State Phenom. 99-100, 181 (2004).

[2] V. Ciupina, G. Prodan, F. Dumitrache, I. Morjan, R. Alexandrescu, E. Popovici, I. Soare, L. Albu, R. Birjega, B. David, O. Schneeweiss, Proc. SPIE 5924, 5924181 (2005).

[3] S. Mørup, J.A. Dumesic, H. Topsøe, in: Applications of Mössbauer Spectroscopy, Ed. R.L. Cohen, Academic Press, New York 1980, p. 1.

[4] W.H. Meiklejohn, C.P. Bean, Phys. Rev. 105, 904 (1957).

[5] R.D. Shull, L.H. Bennett, NanoStructured Materials 1, 83 (1992).

[6] R.M. Cornell, U. Schwertmann, The Iron Oxides, VCH Publishers, Weinheim 1996, Ch. 7.

[7] U. Gonser, Mössbauer Spectroscopy, Springer Verlag, Berlin 1975, Ch. 1.

[8] C.C. Yang, M.X. Xiao, W. Li, Q. Jiang, Solid State Commun. 139, 148 (2006).

[9] J. Cieslak, B.F.O. Costa, S.M. Dubiel, M. Reissner, W. Steiner, J. Phys., Condens. Matter 16, L343 (2004).

[10] J.J. Lu, H.Y. Deng, H.L. Huang, J. Magn. Magn. Mater. 209, 37 (2000). 